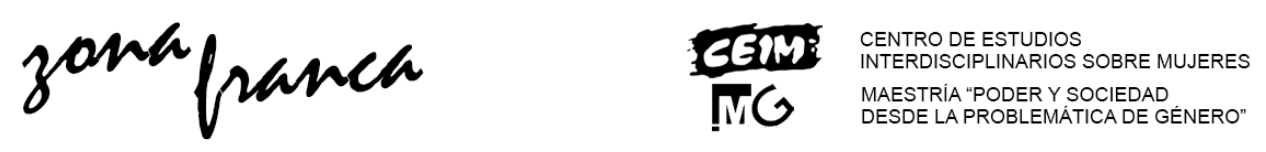

\title{
Martin, María Pía y Pasquali, Laura (Directoras) (2018) Género, Memoria e Identidad. Historias de las trabajadoras de la carne del Swift Rosario (1930- 1940), Rosario, Instituto de Investigaciones Socio-Históricas Regionales CONICET, 140 pp., ISBN 978-987-25834-7-7.
}

Este libro es una apuesta a articular la historia investigada con la historia enseñada y surge como resultado de las prácticas docentes y de investigación de sus autoras en los espacios públicos de enseñanza. El Instituto de Enseñanza Superior N 28 "Olga Cossettini" y el ISHIR- Investigaciones Sociohistóricas Regionales del CONICET son las dos instituciones públicas en las que se gesta un proyecto de trabajo cuya consecuencia es esta producción escrita. Género, Memoria e Identidad está escrito por docentes que piensan y producen materiales para el trabajo en las aulas. En una coyuntura socioeducativa adversa como la actual, este libro reivindica los escenarios educativos y los ámbitos de la investigación histórica públicos como posibilitadores de construcciones colectivas singulares.

Se trata de cuatro capítulos que se tejen cada uno con propuestas y documentos para el trabajo en el aula. El libro que se presenta indaga en las memorias de las trabajadoras del Frigorífico Swift, instalado en la ciudad de

\footnotetext{
*Prof. De Historia (UNL) Mg. En Ciencias Sociales (UNQ) Becaria Doctoral (ISHIR-CONICET-UBA)
}

Revista Zona Franca- Centro de estudios interdisciplinario sobre las mujeres (CEIM)- Maestría poder y sociedad desde la problemática de género (MG), Rosario, Argentina. ISSN, 2545-6504 http://zonafranca.unr.edu.ar/index.php/ZonaFranca| Numero 26 (2018). 
Rosario entre 1917 y 1924. Las autoras visibilizan la participación política y sindical de estas mujeres y exploran, desde una perspectiva de género, las representaciones que sobre ellas se construyeron en la comunidad de El Saladillo y aquellas que se plasmaron en la prensa obrera y en la revista de la patronal Swiftlandia.

En el Capítulo 1, Roxana Cáceres y Flavia Mansilla estudian la conformación del barrio El Saladillo como espacio local en el que se construyeron y se situaron las identidades de una comunidad popular. La interrelación entre la vida laboral y la vida cotidiana generaron un espacio moldeado por la actividad industrial que hacia la década de 1930 impregnó de rasgos populares a la comunidad barrial. Las autoras recorren el proceso histórico de constitución del barrio, de las instituciones políticas y gremiales, de las luchas por mejorar las condiciones de vida y de trabajo y en este sentido, recuperan los elementos que dan cuenta de una identidad obrera. La vida cotidiana en el Barrio Popular El Saladillo puede estudiarse a partir de recursos documentales que son puestos a consideración de los docentes en el anexo pedagógico con el objetivo de abordar la temática de la identidad barrial.

La presencia de las mujeres obreras en el frigorífico Swift y sus formas de participación y lucha son recuperadas por Débora Contadin en el capítulo 2. La autora no solo se propone visibilizar la lucha obrera de las mujeres en la huelga de 1930, sino que recorre las representaciones e imágenes que sobre las mujeres permeaban a la sociedad Argentina de esa época. La asociación entre mujer y 
maternidad imperaba como condición fundamental para explicar que las mujeres debían encargarse de las tareas del hogar, de sus hijos y también de sus maridos en el espacio privado. Los estereotipos sociales que consideraban a las mujeres débiles y sensibles se acompañaban de los deberes que ellas debían cumplir. En la comunidad de El Saladillo esto se expresaba en una serie de prejuicios y concepciones que colocaban a los hombres como dueños y dominantes del espacio de trabajo, masculinizado, ordenado según la división sexual del trabajo y sostenido en estos preceptos morales que moldeaban las prácticas privadas y públicas de los habitantes de la comunidad. En este sentido, Contadin se ocupa de mostrar a través de una coyuntura conflictiva, en este caso la huelga en el frigorífico en 1930 que las trabajadoras de la carne participaron activamente de las acciones de lucha y en la dinámica sindical con los varones. La perspectiva de género para estudiar este conflicto le permite a la autora poner en tensión la esfera de las representaciones sociales sobre las mujeres y la esfera de las experiencias concretas en el lugar de trabajo y en los ámbitos públicos. De esta manera contribuye con fuentes de la prensa y, testimonios orales para ser utilizadas en las aulas en pos de instalar la problemática del trabajo femenino.

El capítulo 3, escrito por Alejandra Pistacchi y titulado "La Carne al desnudo. Acerca de los relatos sobre la exposición del cuerpo femenino como castigo" se ocupa de indagar el mundo de las memorias individuales y colectivas sobre los recuerdos que trabajadores y trabajadoras tienen de jornadas en las que mujeres empleadas en el frigorífico fueron desnudadas y consideradas "carneras" porque desafiaron una huelga y fueron castigadas. La falta de registros sobre 
estos hechos en la prensa no le impidieron a Pistacchi interpretar esas memorias, resultado de la realización de entrevistas, como expresión de marcos sociales en los que esos relatos estaban insertos. De esta manera, la autora recorre las representaciones sociales, los valores imperantes y relacionados con concepciones de género vigentes en los años $30^{\prime}$ y $40^{\prime}$ del siglo $X X$ que corresponde a los períodos en los que estos conflictos tuvieron lugar. Las formas de recordar, las maneras de decir de los testimoniantes son analizadas por la autora observando nociones construidas con la impronta del imaginario del siglo XIX las que, como se desarrolla en el capítulo anterior, estereotipan a las mujeres según sus atributos físicos y su "inferioridad" con relación a los varones. La propuesta para el trabajo en el aula que corresponde a los temas de este capítulo pretende articular pasado y presente. Se invita a los y las docentes a trabajar con variadas fuentes históricas con el objetivo de reflexionar e interpretar las significaciones de la vestimenta y la identidad trabajadora como también la desnudez de la mujer puesta en el espacio público en las protestas actuales.

¿Cuáles y cómo eran los discursos del patrón sobre el mundo del trabajo en Swift?, esta pregunta general se desprende del último capítulo de este libro escrito por Beatriz Argiroffo. La autora explora en el "mundo ideal" construido por la patronal y plasmado en la revista Swiftlandia que, a partir de 1943, se convirtió en la publicación mensual y gratuita destinada al personal de la planta. A través del análisis de los temas, notas y demás contenidos de la revista Argiroffo, recupera los intereses de la empresa en pos de construir una identidad del personal alejada de conflictos y destacando, con lenguaje amigable, paternalista y festivo, los 
acontecimientos que se reconocían como forma de integrar y disciplinar al personal. Resulta interesante este capítulo porque se analiza la forma en que la revista habla de las mujeres trabajadoras desde una mirada patriarcal y androcéntrica, y resulta acertado el esfuerzo por contrastar estas representaciones con las otras que aparecían en la prensa obrera. En este mismo sentido, es metodológicamente significativa la utilización de fuentes orales para tensionar las imágenes de una realidad laboral idealizada plasmada en la revista. Las fuentes históricas (letras de tango, imágenes) que se proponen para ser trabajadas en el aula y las estrategias pedagógicas que se sugieren a los docentes enriquecen la investigación histórica que la autora construye en el capítulo. Sus propuestas invitan a despertar las sensibilidades de los alumnos y alumnas para interrogar a las fuentes.

Tender puentes entre la investigación y la enseñanza en las aulas de la escuela secundaria no es tarea sencilla (Maestro Gonzalez, P. (2005). ¿Cómo enseñar historia? ¿Qué historia enseñar? ¿Para quienes? Son cuestiones que se ponen en juego cuando el y la docente planifica, selecciona contenidos, piensa desde una concepción de la enseñanza dialéctica y no bancaria con el propósito de crear condiciones de aprendizaje con los alumnos. Los capítulos de este libro tienen la virtud de explorar temas, problemas y metodologías que no siempre son incorporados en la currícula de la historia enseñada, la que generalmente está colonizada por perspectivas androcéntricas (para explicar los procesos y cambios sociales) y generalizaciones emanadas desde una historia nacional con centro porteño. En este sentido, las historias de las trabajadoras de la carne del Swift de 
Rosario son colocadas como experiencias peculiares que merecen ser interrogadas. ¿Por qué?, se pregunta Beatriz Argiroffo en el capítulo de su autoría, luego de leer el libro considero que es necesario e importante otorgar de significado histórico a las prácticas laborales de las mujeres en el espacio local, a sus relatos y memorias. Prácticas que se leen desde la perspectiva de género para poder deconstruir los ámbitos laborales considerados típicamente masculinos, como también los espacios de lucha social asignados socialmente a los varones. Los capítulos que se hilvanan en este libro contribuyen a la historiografía en esos sentidos y reivindican las maneras de estar y actuar en los espacios, como lugares constitutivos de la identidad.

\section{Bibliografía}

MAESTRO GONZALEZ, Pilar (2005). Historiografía, Didáctica y Enseñanza de la Historia. Clío \& Asociados. La Historia Enseñada, 1(2), 9-34. https://doi.org/10.14409/cya.v1i2.1505

Revista Zona Franca- Centro de estudios interdisciplinario sobre las mujeres (CEIM)- Maestría poder y sociedad desde la problemática de género (MG), Rosario, Argentina. ISSN, 2545-6504 http://zonafranca.unr.edu.ar/index.php/ZonaFrancal Numero 26 (2018). 